respiratory tract infections. Understanding the immunological effects of different particle types will help guide public health interventions.

\section{P122 LOCAL SOURCES RATHER THAN INTERACTIONS WITH OXIDISING CO-POLLUTANT GASES DETERMINE THE GEOGRAPHICAL AND SEASONAL VARIATION IN PARTICULATE MATTER OXIDATIVE POTENTIAL}

N Camina, DC Green, FJ Kelly, IS Mudway. King's College London, London, UK

\subsection{6/thoraxjnl-2016-209333.265}

Background Reactions of ambient particulate matter (PM) with atmospheric radicals and oxidising gases such as nitrogen dioxide $\left(\mathrm{NO}_{2}\right)$ and ozone $\left(\mathrm{O}_{3}\right)$ may alter their toxicity - often referred to as particle ageing. As concentrations of $\mathrm{O}_{3}$ dominate in the warmer months, with $\mathrm{NO}_{2}$ episodes more common in the winter, we investigated whether seasonal differences in the PM oxidative potential (the capacity of inhaled PM to cause damaging oxidation reactions at the air-lung interface) could be attributed to their interaction with these gases.

Methods Daily $\mathrm{PM}_{10}$ and $\mathrm{PM}_{2.5}$ filters from 4 sites in Southern England were obtained during summer $\left(21^{\text {st }}\right.$ July $-23^{\text {rd }}$ August $)$ and winter $\left(6^{\text {th }}\right.$ Jan-1 $1^{\text {th }}$ Feb) campaigns in 2012: two sites in London, roadside (Marylebone Road) and urban background (North Kensington) locations, plus two rural sites to the West (Harwell) and East (Detling) of the city. Ascorbate and glutathione-dependent oxidative potential $\left(\mathrm{OP}^{\mathrm{AA}}\right.$ and $\mathrm{OP}^{\mathrm{GSH}}$, expressed per unit mass of PM) were then determined following incubation in a synthetic respiratory tract lining fluid (4 hours at $37^{\circ} \mathrm{C}, \mathrm{pH} 7.0$ ) using a novel on filter methodology.

Results In terms of the $\mathrm{OP}^{\mathrm{AA}}$ metric only $\mathrm{PM}_{2.5}$ measured at the urban background location demonstrated a seasonal increase ( $\mathrm{p}<0.05$ ) during the summer, with equivalent seasonal OPs across the remaining 3 sites and no differences apparent in $\mathrm{PM}_{10}$.
In contrast, $\mathrm{PM}_{10}$ and $\mathrm{PM}_{2.5} \quad \mathrm{OP}^{\mathrm{GSH}}$ was significantly $(\mathrm{P}<0.001)$ lower in the summer period at the urban background site. Summer increases in $\mathrm{OP}^{\mathrm{GSH}}$ were observed at the rural sites, with evidence that summer $\mathrm{PM}_{2.5} \mathrm{OP}^{\mathrm{GSH}}$ was increased at the roadside site. This heterogeneous pattern of seasonal contrasts could not be simplistically related to the differences in period, or daily $\mathrm{NO}_{2}$ or $\mathrm{O}_{3}$ concentrations.

Conclusions No consistent seasonal pattern in $\mathrm{PM}_{10}$ or $\mathrm{PM}_{2.5}$ OP was observed across the four sites and the associations between the measured particulate OPs with $\mathrm{O}_{3}$ and $\mathrm{NO}_{2}$ at these locations did not fit with the particle ageing hypothesis. Rather high OP days were often found to be associated with wind speed and direction, suggesting that the differences were driven by a combination of long and short range sources.

\section{P123 WHAT CAUSES OCCUPATIONAL ASTHMA IN CLEANERS?}

${ }^{1}$ VC Moore, ${ }^{1} P S$ Burge, ${ }^{2}$ AS Robertson, ${ }^{1} E D$ Parkes, ${ }^{1} \mathrm{GI}$ Walters. ${ }^{1}$ Birmingham Heartlands Hospital, Birmingham, UK; '2University Hospitals Birmingham, Birmingham, UK

\subsection{6/thoraxjnl-2016-209333.266}

Domestic cleaners show a consistently raised risk of developing asthma in population-based epidemiological studies. The main risks appear to be the use of bleach and sprayed cleaning agents. These risks are now found in other occupations, such as healthcare due to the requirement for disinfection of clinical areas. Since 2000, there has been 26 cleaners and healthcare workers with occupational asthma (OA) reported to Shield (West Midlands registry for $\mathrm{OA}$ ) thought to be due to cleaning agents. The majority of these were using chlorine-releasing substances containing dichloro-isocyanurate for disinfection purposes. We have carried out 8 specific inhalation challenge tests to chlorine-releasing tablets mixed with cold water but none of these have elicited an asthmatic reaction despite the workers previously showing work-related changes on serial peak flows when exposed. In a

Abstract P123 Figure 1 Specific inhalation challenge testing showed no asthmatic response to hartabs or urine alone. The chlorine urine mixture provoked a dual asthmatic reaction and sustained drop in FEV1 of up to $34 \%$ from base line. The grey box denotes the exposure. 